\title{
Effect of doping concentration on the structural, morphological, optical and electrical properties of Mn-doped CdO thin films
}

\author{
N. Manjula, M. Pugalenthi, V.S. Nagarethinam, K. Usharani, A.R. Balu*
}

PG and Research Department of Physics, A.V.V.M. Sri Pushpam College, Poondi-613 503, Thanjavur (Dt), Tamilnadu, India

\begin{abstract}
Thin films of manganese-doped cadmium oxide (CdO:Mn) with different Mn-doping levels (0, 1, 2, 3 and 4 at.\%) were deposited on glass substrates by employing an inexpensive, simplified spray technique using a perfume atomizer at $375{ }^{\circ} \mathrm{C}$. The influence of $\mathrm{Mn}$ incorporation on the structural, morphological, optical and electrical properties of CdO films has been studied. All the films exhibit cubic crystal structure with a (1 111 ) preferential orientation. Mn-doping causes a slight shift of the (1 111$)$ diffraction peak towards higher angle. The crystallite size of the films is found to decrease from $34.63 \mathrm{~nm}$ to $17.68 \mathrm{~nm}$ with an increase in Mn doping concentration. The CdO:Mn film coated with 1 at.\% Mn exhibit a high transparency of nearly $90 \%$ which decreases for higher doping concentration. The optical band gap decreases with an increase in Mn doping concentration. All the films have electrical resistivity of the order of $10^{-4} \Omega \cdot \mathrm{cm}$.
\end{abstract}

Keywords: X-ray diffraction; crystal structure; thin film; optical properties; electrical properties

(C) Wroclaw University of Technology.

\section{Introduction}

Cadmium oxide $(\mathrm{CdO})$ based transparent conducting film is widely used in photovoltaic and optoelectronic applications because of its low electrical resistivity and high optical transparency [1]. Pure $\mathrm{CdO}$ is an n-type degenerate semiconductor with high electrical conductivity $\left(10^{2}\right.$ to $\left.10^{4} \mathrm{~S} / \mathrm{cm}\right)$ which may be due to defects of oxygen vacancies and cadmium interstitials [2]. The high electrical conductivity and optical transmittance in the visible region of solar spectrum make $\mathrm{CdO}$ thin film suitable for various applications, such as solar cells, phototransistors, photodiodes, etc. [3]. However, the low band gap energy $\left(\mathrm{E}_{\mathrm{g}}\right)$ of $\mathrm{CdO}$ restricts its potential applications, especially in the visible region of solar spectrum. To get rid of this drawback, the band gap of $\mathrm{CdO}$ must be widened without altering its electrical conductivity. There have been earlier reports on the improvement of optical band gap of $\mathrm{CdO}$ by doping with metallic ions, like $\mathrm{Zn}$, Sn, Al, Ti, etc. Usharani et al. [4] have reported

*E-mail: arbalu757@gmail.com an improvement in the optical band gap of $\mathrm{CdO}$ by zinc incorporation. Ferekides et al. [5] reported that In doping can enhance the optical band gap of $\mathrm{CdO}$ thin films. It was observed that when $\mathrm{CdO}$ is doped with rare earth oxides, its optical band gap can be widened. Gupta et al. [6] have reported that doping of $\mathrm{CdO}$ with gadolinium: a rare earth element, can enhance its band gap. Recently, it was observed that doping of $\mathrm{CdO}$ with magnetic ions, like Fe [7], Li [8], combines some magnetic properties with its optoelectronic properties for different applications. In general, it was observed that doping of $\mathrm{CdO}$ with metallic ions having ionic radius smaller than that of $\mathrm{Cd}^{2+}$, can improve its electrical conduction and increase its optical band gap energy. Manganese (Mn) is an oxalate material from $3 \mathrm{~d}$ series, isomorphous in nature, having low decomposition temperature, which when doped in oxide semiconductors can modify their physical properties. Mn-doped $\mathrm{CdO}$ films were synthesized by de Biasi and Grillo at $1100{ }^{\circ} \mathrm{C}$ [9]. They measured the electron magnetic resonance (EMR) line widths of $\mathrm{Mn}^{2+}$ in $\mathrm{CdO}$ up to $1.0 \mathrm{~mol} \%$ concentration. Ahmad et al. [10] synthesized $\mathrm{Cd}_{1-\mathrm{x}} \mathrm{Mn}_{\mathrm{x}} \mathrm{O}$ 
nanoparticles by solvothermal method using $\mathrm{Mn}$ as an oxalate precursor. They showed that the optical band gap of $\mathrm{CdO}$ increased with $\mathrm{Mn}$ doping. This clearly shows that Mn doping can also enhance the band gap of CdO. Motivated by this fact in the present work, Mn-doped $\mathrm{CdO}$ thin films with $\mathrm{Mn}$ concentrations $(0,1,2,3$ and 4 at.\%) were deposited on glass substrates at $375{ }^{\circ} \mathrm{C}$ by spray pyrolysis technique using a perfume atomizer and the effects on the structural, morphological, optical and electrical properties of the $\mathrm{CdO}$ films due to Mn doping were investigated. The use of a perfume atomizer has some specific advantages over the conventional spray technique which uses a spray gun assembly: low cost, no need for carrier gas, fine atomization, improved wettability between the sprayed microparticles, and almost nil loss of the precursor to the surroundings. Recently, we have reported that this simplified spray technique can be a desired alternative for the conventional spray technique by successfully fabricating Mg-doped CdS thin films [11].

\section{Experimental}

$\mathrm{CdO}$ and $\mathrm{Mn}$-doped $\mathrm{CdO}$ thin films were prepared from an aqueous solution containing $0.1 \mathrm{M}$ cadmium acetate, $\mathrm{Cd}(\mathrm{CHCOO})_{2}$ dissolved in $50 \mathrm{~mL}$ of deionized water. Manganese acetate, $\mathrm{Mn}\left(\mathrm{CH}_{3} \mathrm{COO}\right)_{2}$ was added to the starting solution for Mn doping in a concentration of $0,1,2,3$ and 4 at.\%. The precursor salts used were of analytical reagent grade with a purity of $99.8 \%$ (supplied by Sigma-Aldrich). The resulting solution was stirred thoroughly using a magnetic stirrer for $30 \mathrm{~min}$ and then sprayed manually using a perfume atomizer on glass substrates kept at $375{ }^{\circ} \mathrm{C}$. Before deposition, the glass substrates were degreased with an organic solvent, rinsed with deionized water and dried in air. A profilometer (Surftest SJ-301) was used to measure the thicknesses of the films. Diffractometer X'Pert PRO model, using CuK $\alpha$ radiation $(\lambda=1.5406 \AA)$ with $2 \theta$ ranging from $20^{\circ}$ to $80^{\circ}$ was used to determine the structure, crystallinity and phase of the $\mathrm{CdO}$ and $\mathrm{CdO}: \mathrm{Mn}$ thin films. The surface morphology of the films was characterized by scanning electron microscope
Hitachi model S-3000H. Optical transmission studies were carried out using PerkinElmer UV-VisNIR double beam spectrophotometer (LAMBDA35). Measurements of electrical resistivity were carried out with a four-point probe setup.

\section{Results and discussion}

\subsection{Chemical composition studies}

Fig. 1 shows the variation of atomic percentages of $\mathrm{Cd}, \mathrm{O}$ and $\mathrm{Mn}$ in CdO:Mn films deposited with different Mn doping concentrations (0, 1, 2, 3 and 4 at.\%) in the starting solution.

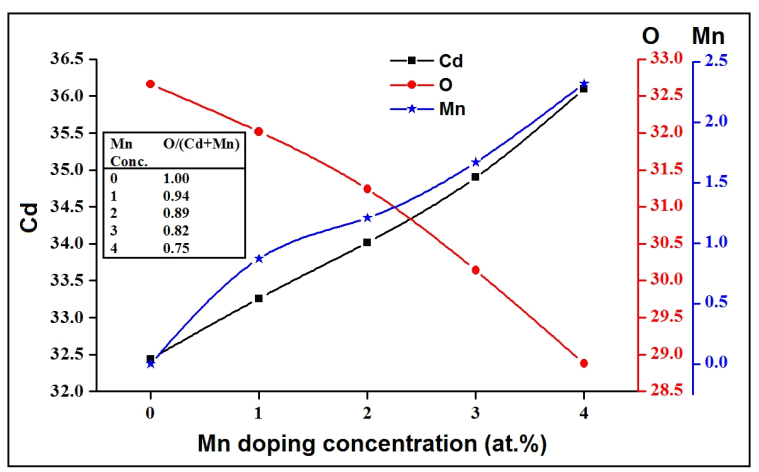

Fig. 1. Variation of the concentration of $\mathrm{Cd}, \mathrm{O}$ and $\mathrm{Mn}$ in the CdO:Mn films.

It is observed that the amount of Mn increases linearly with an increase in doping concentration. It is also observed that $\mathrm{Cd}$ content increases, whereas O content decreases with $\mathrm{Mn}$ doping concentration. If $\mathrm{Mn}^{2+}$ ions successfully replaced $\mathrm{Cd}^{2+}$ ions, a decrement in $\mathrm{Cd}$ content should be observed with increased content of $\mathrm{Mn}$. The converse result obtained here confirms that $\mathrm{Mn}^{2+}$ ions have not effectively replaced $\mathrm{Cd}^{2+}$ ions in the $\mathrm{CdO}$ host lattice. The inset Table shows that the $\mathrm{O} /(\mathrm{Cd}+\mathrm{Mn})$ ratio decreases with an increase in Mn doping concentration suggesting the deterioration of the crystallinity of the $\mathrm{CdO}$ films with doping which is confirmed by the structural analysis (Section 3.2).

\subsection{Structural studies}

The X-ray diffraction patterns of Mn-doped $\mathrm{CdO}$ thin films deposited with different $\mathrm{Mn}$ 


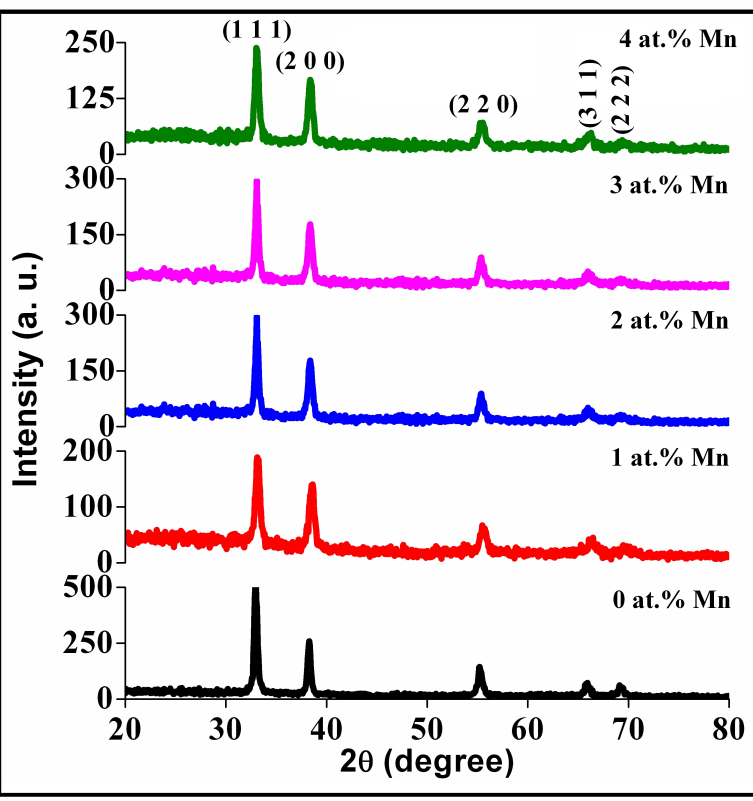

Fig. 2. XRD patterns of Mn-doped CdO thin films.

concentrations $0,1,2,3$ and 4 at.\% in the starting solution are shown in Fig. 2.

From the patterns, it is clear that the films are polycrystalline in nature with diffraction patterns at $2 \theta=32.9^{\circ}, 38.2^{\circ}, 55.2^{\circ}, 65.83^{\circ}$ and $69.17^{\circ}$ in-

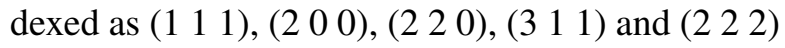
planes of cubic CdO (JCPDS Card No. 73-2245). The comparison of observed and standard ' $d$ ' values of the CdO:Mn films are given in Table 1.

The matching of the calculated $d_{h k l}$ values and the standard ones confirms that all the deposited films (undoped and Mn-doped $\mathrm{CdO}$ ) crystallize well in the cubic structure with a preferred orientation of the crystallites along the [llll 111$]$ direction. The behaviour of preferential growth along the $\left(\begin{array}{lll}1 & 1 & 1\end{array}\right)$ plane was also observed by Shanmugavel et al. [12] for $\mathrm{CdO}$ thin films prepared by spray technique using a perfume atomizer. The preferred growth of the $\left(\begin{array}{lll}1 & 1 & 1\end{array}\right)$ plane for all the films remained predominant irrespective of $\mathrm{Mn}$ doping level. No peaks corresponding to $\mathrm{MnO}$ or $\mathrm{Cd}(\mathrm{OH})_{2}$ were detected in the XRD patterns, suggesting that incorporation of $\mathrm{Mn}^{2+}$ ions in the host $\mathrm{CdO}$ lattice did not affect its crystal structure.

The variation of preferential orientation factor

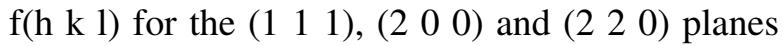



Fig. 3. Variation of $\mathrm{f}(\mathrm{h} \mathrm{kl})$ of $\mathrm{CdO}: \mathrm{Mn}$ thin films.

as a function of Mn doping concentration is shown in Fig. 3.

It is observed that $\mathrm{f}\left(\begin{array}{lll}1 & 1 & 1\end{array}\right)$ decreases as $\mathrm{Mn}$ concentration increases suggesting a gradual degradation in the crystalline quality of the $\mathrm{CdO}$ films with Mn doping. The deterioration of crystalline quality of $\mathrm{CdO}$ films with $\mathrm{Mn}$ doping may be attributed to the deformation in the $\mathrm{CdO}$ lattice induced by the size difference between $\mathrm{Cd}$ and $\mathrm{Mn}$ ions and also due to the segregation of $\mathrm{Mn}^{2+}$ ions in the grain boundaries of the host $\mathrm{CdO}$ lattice. This is in accordance with Ziabari et al. [13] for Al-doped $\mathrm{CdO}$ thin films prepared by sol-gel dip coating technique. The preferential orientation factor $\mathrm{f}\left(\begin{array}{l}2 \\ 0\end{array} 0\right)$ shows an opposite behavior, which confirms that the preferential orientation starts changing from (lll $\left.\begin{array}{lll}1 & 1 & 1\end{array}\right)$ to $\left(\begin{array}{lll}2 & 0 & 0\end{array}\right)$ plane. This is a consequence of reorientational effect in the crystalline structure of $\mathrm{CdO}$ with doping level. Similar results have been reported by Manjula et al. [14]. The results obtained here infer that the structural properties of the $\mathrm{CdO}$ thin films are strongly influenced by the Mn doping concentration in the starting solution.

Fig. 4 shows a shift of the (llll 11 ) peak towards higher angle with the increase in manganese concentration which results from the fact that $\mathrm{Cd}^{2+}$ ions are substituted by $\mathrm{Mn}^{2+}$ ions in the host lattice, causing the lattice shrinkage (decreased lattice parameter values, Table 2) as the ionic radius 
Table 1. Comparison of observed and standard d-spacing values of Mn-doped CdO thin films.

\begin{tabular}{|c|c|c|c|c|c|c|}
\hline \multirow{3}{*}{ (h k l) } & \multirow{3}{*}{$d-\operatorname{standard}^{*}(\AA)$} & \multicolumn{5}{|c|}{ d-observed $(\AA)$} \\
\hline & & \multicolumn{5}{|c|}{ Mn concentration (at.\%) } \\
\hline & & 0 & 1 & 2 & 3 & 4 \\
\hline$\left(\begin{array}{lll}1 & 1 & 1\end{array}\right)$ & 2.7129 & 2.7172 & 2.7091 & 2.7087 & 2.7053 & 2.7023 \\
\hline$\left(\begin{array}{lll}2 & 0 & 0\end{array}\right)$ & 2.3495 & 2.3520 & 2.3461 & 2.3450 & 2.3394 & 2.3370 \\
\hline$\left(\begin{array}{lll}2 & 2 & 0\end{array}\right)$ & 1.6613 & 1.6621 & 1.6591 & 1.6568 & 1.6533 & 1.6532 \\
\hline$\left(\begin{array}{lll}3 & 1 & 1\end{array}\right)$ & 1.4168 & 1.4175 & 1.4143 & 1.4141 & 1.4100 & 1.4099 \\
\hline$\left(\begin{array}{lll}2 & 2 & 2\end{array}\right)$ & 1.3564 & 1.3570 & 1.3551 & 1.3524 & 1.3511 & 1.3482 \\
\hline
\end{tabular}

*JCPDS Card No. 73-2245

of $\mathrm{Mn}^{2+}(0.67 \AA)$ is smaller than that of $\mathrm{Cd}^{2+}$ $(0.97 \AA)$.

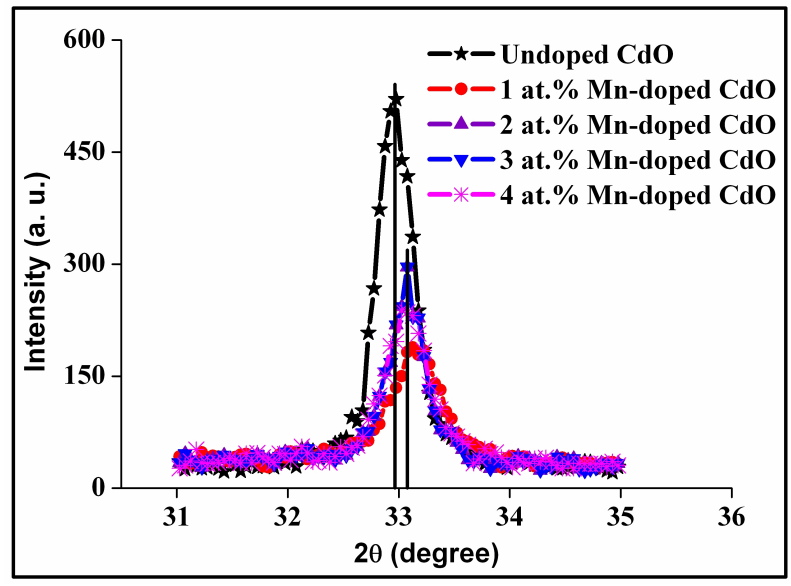

Fig. 4. Angle shift of the (llll) plane.

The crystallite size, (D) is calculated using the Scherrer formula:

$$
D=\frac{0.94 \lambda}{\beta \cos \theta}
$$

where $\beta$ is the broadening of diffraction line measured at half of its maximum intensity (radian) FWHM and $\lambda$ is the wavelength of the X-ray used (1.5406 $\AA$ ). The crystallite size values calculated for the (llll 111 ) plane for different Mn doping concentrations are presented in Table 2.

The crystallite size declines gradually as the Mn doping level in the starting solution increases and attains a minimum value of $17.68 \mathrm{~nm}$ for the film coated with 4 at.\% Mn. This decrease in crystallite size may be caused by the enhanced incorporation of $\mathrm{Mn}^{2+}$ ions into the $\mathrm{Cd}^{2+}$ sites of the host $\mathrm{CdO}$ lattice. The decrease of crystallite size means deteroriation of crystalline quality of $\mathrm{CdO}$ films with Mn doping and an increase of total grain boundary fraction in the films, which can enhance grain boundary scattering, thus, result in an increase of electrical resistivity [15]. The increased resistivity values obtained for the films (section 3.5) strongly support this supposition. When $\mathrm{CdO}$ is doped with $\mathrm{Mn}$, the Mn ions can uniformly substitute into the $\mathrm{Cd}^{2+}$ sites or interstitial sites in the $\mathrm{CdO}$ lattice. In case of successful substitution of $\mathrm{Mn}^{2+}$ ions and due to different ionic radii, a lattice distortion occurs and this distortion increases with increased Mn content, preventing the grain growth. Therefore, a decrease in grain size is observed with an increase in the Mn content. Similar results were reported for cobalt doped $\mathrm{CdO}$ thin films [16].s

The strain present in the samples is calculated using the formula [17]:

$$
\varepsilon=\frac{1}{D^{2}}
$$

and the obtained values are presented in Table 2 . It is observed that the strain values show an increasing trend with increased concentration of $\mathrm{Mn}$ confirming the deterioration of the crystalline quality of the $\mathrm{CdO}$ films with $\mathrm{Mn}$ doping. Mallika et al. [18] reported that an increase of strain causes reduction of crystallite size and increase of peak broadening. 
Table 2. Thickness (t), full width at half maximum ( $\beta$ ), crystallite size (D), strain $(\varepsilon)$ and lattice parameter (a) of the CdO:Mn films.

\begin{tabular}{cccccc}
\hline $\begin{array}{c}\text { Mn doping } \\
\text { concentration (at.\%) }\end{array}$ & $\begin{array}{c}\text { Thickness } \\
\mathrm{t}(\mathrm{nm})\end{array}$ & $\begin{array}{c}\text { Full width at half maximum } \\
\beta \text { (radians) }\end{array}$ & $\begin{array}{c}\text { Crystallite size } \\
\mathrm{D}(\mathrm{nm})\end{array}$ & \multicolumn{2}{c}{ Strain } \\
$\varepsilon \times 10^{-3}$ & Lattice parameter \\
\hline \hline 0 & 497 & 0.25 & 34.63 & 4.182 & 4.7063 \\
1 & 460 & 0.36 & 24.05 & 6.021 & 4.6923 \\
2 & 510 & 0.41 & 21.12 & 6.856 & 4.6916 \\
3 & 492 & 0.44 & 19.68 & 7.359 & 4.6857 \\
4 & 478 & 0.49 & 17.68 & 8.193 & 4.6805 \\
\hline
\end{tabular}

\subsection{SEM analysis}

Fig. 5 shows the SEM micrographs of $\mathrm{CdO}$ films coated with $\mathrm{Mn}$ at different doping levels ( 0 , $1,2,3$ and 4 at.\%).

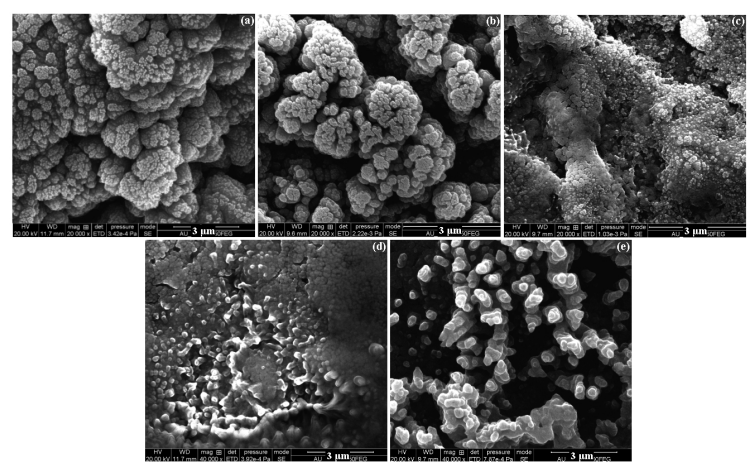

Fig. 5. SEM images of (a) undoped $\mathrm{CdO}$ (b) 1 at.\% $\mathrm{Mn}$ (c) 2 at.\% Mn (d) 3 at.\% Mn and (e) 4 at.\% Mn doped $\mathrm{CdO}$ films.

From Fig. 5, it is observed that the microstructure of the $\mathrm{CdO}$ films is governed strongly by the Mn doping level. The SEM micrograph of the undoped CdO film (Fig. 5a) is composed of densely packed cauliflower shaped nanostructures. These structures, which might have been formed from interwoven nanorods, have a great importance due to their high specific surface area and potential applications in various fields [4]. As the Mn doping concentration is increased to 1 at.\%, the film surface modifies with loosely packed cauliflower structures (Fig. 5b). Traces of few empty sites are also observed. With further doping, the surface is fully modified with interconnected tiny cauliflower structures for the film coated with 2 at. $\% \mathrm{Mn}$ (Fig. 5c). For 3 at.\% Mn doping concentration, no cauliflower shaped structures are seen (Fig. 5d). Island growth with interconnected grains is observed. However, for the film coated with 4 at.\% Mn doping concentration the surface modifies completely, covering with scattered grains (Fig. 5e). These results infer that the surface morphology of $\mathrm{CdO}$ thin film deteriorates with $\mathrm{Mn}$ doping from cauliflower shaped nanostructures to loosely bounded grains which very well acknowledges the results obtained in the XRD analysis (section 3.2).

\subsection{Elemental analysis}

Fig. 6 shows the representative EDS spectra of undoped and CdO:Mn (Mn doping level: 1 at.\%) films, respectively.

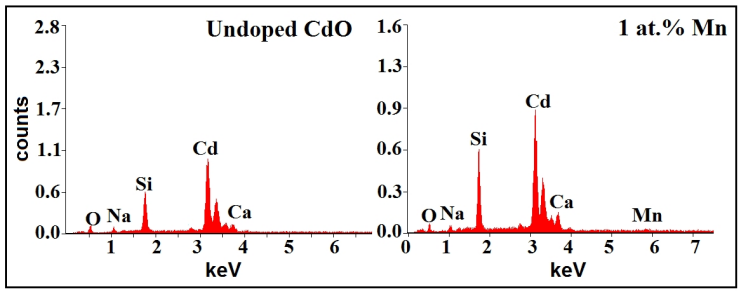

Fig. 6. EDS spectra of undoped and Mn-doped CdO (Mn doping level: 1 at.\%) films.

The EDS spectra confirm the presence of $\mathrm{Cd}, \mathrm{O}$ in the undoped samples and $\mathrm{Cd}, \mathrm{O}$ and $\mathrm{Mn}$ in the doped film. 


\subsection{Optical studies}

Fig. 7 shows the transmittance spectra of CdO:Mn thin films deposited with different $\mathrm{Mn}$ doping concentrations $(0,1,2,3$ and 4 at.\%). The pure $\mathrm{CdO}$ film shows a transparency of $88 \%$ which enhances to $90 \%$ for 1 at.\% Mn doped CdO film.

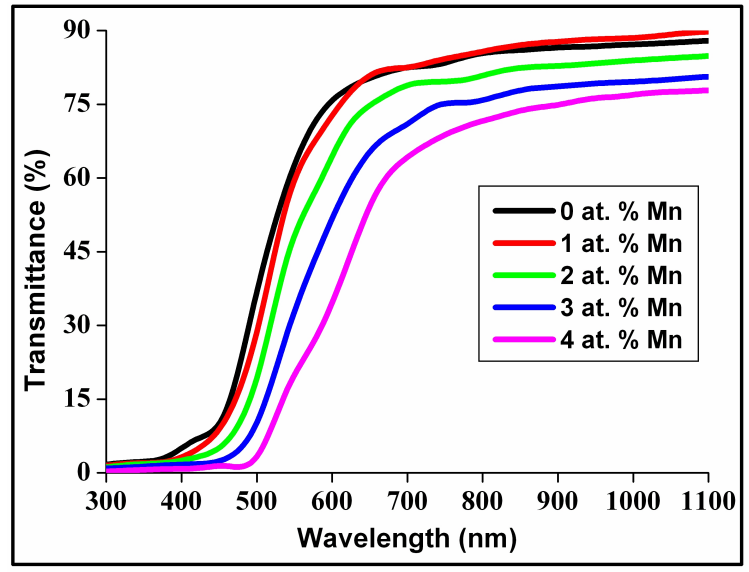

Fig. 7. Transmittance spectra of the CdO:Mn thin films.

The transparency decreases for higher Mn doping concentrations (greater than 1 at.\%) and a minimum value of $78 \%$ is obtained for the film coated with 4 at.\% Mn. Transmission edge shifts towards longer wavelength side as the Mn doping concentration increases which indicates a decrement in the optical band gap of the CdO:Mn films. The decrease in the transparency of CdO:Mn films coated with 2, 3 and 4 at.\% Mn concentration may be due to the incorporation of more $\mathrm{Mn}$ in the $\mathrm{CdO}$ lattice and also a small increase in the free charge carrier concentration [19]. The band gap $\left(\mathrm{E}_{\mathrm{g}}\right)$ values have been estimated by plotting the graph of the first derivative of transmittance with respect to the wavelength $(\mathrm{dT} / \mathrm{d} \lambda)$ versus the photon energy $(\mathrm{h} v)$ (Fig. 8).

The $\mathrm{E}_{g}$ value of the undoped sample is found to be equal to $2.47 \mathrm{eV}$. The band gap value of the CdO:Mn film coated with 1 at. $\%$ Mn concentration was found to be equal to $2.42 \mathrm{eV}$.

When the Mn concentration is increased further, the band gap value decreases and attains a minimum value of $2.21 \mathrm{eV}$ for the film coated with 4 at.\% Mn. The decrease in the optical band gap

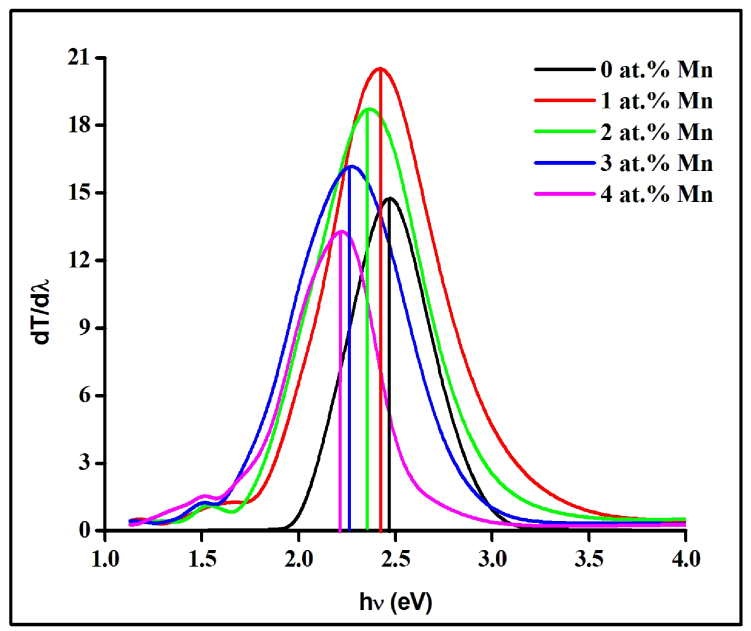

Fig. 8. Variation of the first derivative of transmittance with respect to the wavelength $(\mathrm{dT} / \mathrm{d} \lambda)$ of CdO:Mn thin films versus the photon energy (hv).

observed with the increased Mn doping could be related to the structural deformation in the $\mathrm{CdO}$ films caused due to the replacement of either substitutional or interstitial cadmium ions in the $\mathrm{CdO}$ lattice by Mn ions. The observed red shift in the optical band gap value can be related to the BursteinMoss effect or may be due to the sp-d exchange interactions between the localized d electrons and the band electrons of the $\mathrm{Mn}^{2+}$ ions which substitute Cd ions [20].

\subsection{Electrical studies}

The dependence of electrical resistivity of $\mathrm{CdO}$ films with Mn doping level is shown in Fig. 9.

All the films have resistivity of the order of $10^{-4} \Omega \cdot \mathrm{cm}$. Pure $\mathrm{CdO}$ possess resistivity of $0.19 \times 10^{-4} \Omega \cdot \mathrm{cm}$. The resistivity value increases with Mn doping concentration and attains a maximum value of $0.791 \times 10^{-4} \Omega \cdot \mathrm{cm}$ for the film coated with 4 at.\% Mn. This clearly suggests that Mn atoms are not placed into the $\mathrm{CdO}$ lattice effectively which contradicts with the results obtained in section 3.1. In XRD analysis, it has been observed that the crystallite size decreases linearly with $\mathrm{Mn}$ doping suggesting the enhanced incorporation of $\mathrm{Mn}^{2+}$ ions into the $\mathrm{CdO}$ lattice. If $\mathrm{Mn}$ atoms are placed effectively into the $\mathrm{CdO}$ lattice, they may 


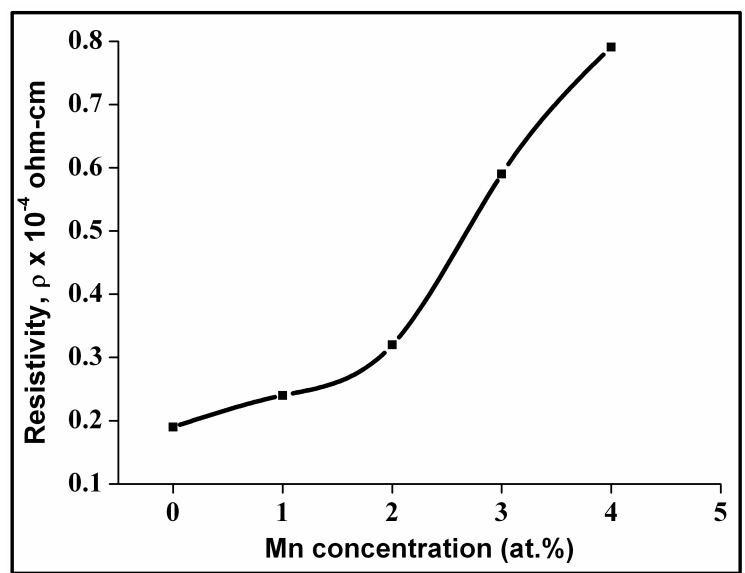

Fig. 9. Electrical resistivity variation of the CdO:Mn films.

act as donors by supplying free electrons when they occupy the sites of $\mathrm{Cd}^{2+}$ ions. Sankarsubramanian et al. [21] reported that $\mathrm{CdO}$ films doped with $\mathrm{Mn}$ showed decreased resistivity only up to $1 \mathrm{wt} . \% \mathrm{Mn}$ and for further increase in Mn doping level the resistivity increased. The resistivity value of $\mathrm{CdO}: \mathrm{Mn}$ (Mn doping level: 1 at.\%) obtained here exactly matches with that of the undoped film and above 1 at.\% Mn it increases, which agrees with the results of Sankarasubramanian et al. So it can be concluded that up to 1 at.\%, $\mathrm{Mn}$ atoms are placed into the $\mathrm{CdO}$ lattice effectively and above that, $\mathrm{Mn}$ ions cannot be accommodated into the $\mathrm{CdO}$ lattice due to their limited solid solubility, therefore, they form neutral $\mathrm{MnO}$ which isolates the grain boundaries, even though the ionic radius of $\mathrm{Mn}^{2+}$ is smaller than that of $\mathrm{Cd}^{2+}$. Thus, increasing the concentration of $\mathrm{Mn}$ beyond 1 at.\% results in the segregation of $\mathrm{Mn}$ atoms in the grain boundaries which in turn increases the grain carriers at the grain boundaries, hence, the resistivity increases.

\subsection{PL studies}

Fig. 10 shows the PL spectra of undoped $\mathrm{CdO}$ and CdO:Mn film with 1 at.\% Mn doping concentration which has the best structural, morphological, optical and electrical properties, excited at $\lambda=290 \mathrm{~nm}$.

The PL spectra of both undoped and doped samples show emission peaks at 327, 337, 361,

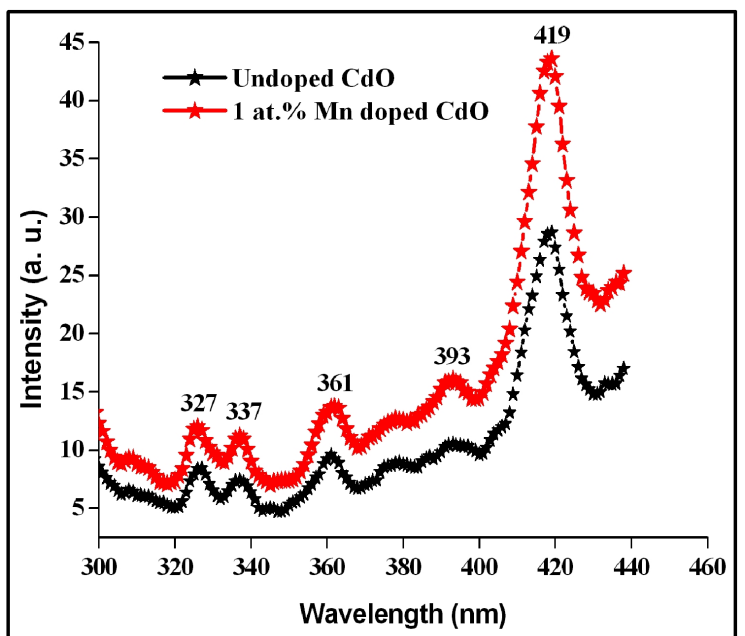

Fig. 10. PL spectra of undoped and CdO:Mn (Mn doping level: 1 at.\%) films.

393 and $419 \mathrm{~nm}$, respectively. The emission peak at $361 \mathrm{~nm}$ is assumed to be caused by the recombination of free excitons. The emission peak observed at $393 \mathrm{~nm}$, which corresponds to the band edge emission is due to the electron transition from the localized level, slightly below the conduction band to the valence band. The peak observed at $393 \mathrm{~nm}$ corresponds to the PL peak of pure $\mathrm{CdO}$ which is located at $3.11 \mathrm{eV}(\sim 399 \mathrm{~nm})$ as reported in the literature [22]. The violet emission peak centered at $419 \mathrm{~nm}$ can be attributed to point defects in $\mathrm{CdO}$ lattice due to $\mathrm{Cd}$ interstitials/O vacancies. The electrons from the conduction band relax in the $\mathrm{Cd}$ interstitial state before transition to the valence band and emit this violet light. This is in accordance with Zeng et al. [23]. The small width peaks observed at 327 and $337 \mathrm{~nm}$ could not be assigned to any emission process but may be regarded as noise [24].

\section{Conclusions}

Highly transparent $\mathrm{Mn}$-doped $\mathrm{CdO}$ thin films with $\mathrm{Mn}$ doping concentrations $(0,1,2,3$ and 4 at.\%) were prepared on glass substrates at $375^{\circ} \mathrm{C}$ using a perfume atomizer. The effect of $\mathrm{Mn}$ doping concentration on the physical properties of the $\mathrm{CdO}$ films was investigated. XRD studies revealed that all the films crystallized in a cubic structure with a preferential orientation along the $\left(\begin{array}{lll}1 & 1 & 1\end{array}\right)$ 
plane. A shift of the $\left(\begin{array}{lll}1 & 1 & 1\end{array}\right)$ peak towards higher angle was observed with $\mathrm{Mn}$ doping. Crystallite size decreased from $34.63 \mathrm{~nm}$ to $17.68 \mathrm{~nm}$ with an increase in Mn doping. A high transmittance of $90 \%$ was observed for the CdO:Mn film with 1 at. $\% \mathrm{Mn}$ concentration and for further increase of doping concentration, it slightly decreased. The band gap energy decreased from $2.47 \mathrm{eV}$ to $2.21 \mathrm{eV}$ with Mn doping and the CdO:Mn film with 1 at.\% Mn doping concentration exhibited a band gap equal to $2.42 \mathrm{eV}$, which exactly matched the band gap value of bulk $\mathrm{CdO}$. Electrical resistivity increased with an increase in Mn doping concentration. The obtained results infer that $\mathrm{Mn}$ as a dopant at a very small concentration $(<2$ at. $\%)$ can alter the structural, morphological optical and electrical properties of the $\mathrm{CdO}$ films.

\section{References}

[1] Gupta R.K., Ghosh K., Patel R., Kahol P.K., Physica E, 44 (2011), 163.

[2] Manjula N., Usharani K., Balu A.R. NAGARETHinam V.S., Int .J. ChemTech. Res., 6 (1) (2014), 705

[3] Yakuphanolu F., Sol. Energy, 85 (2011), 2704.

[4] Usharani K., Balu A.R., Acta Metall. Sin., 4 (2015), 8.

[5] Ferekides C.S., Mamazza R., BalasubramaNIAN U., Morel D.L., Thin Solid Films, 480 (2000), 8180.

[6] Gupta R.K., Serbetei Z., Yakuphanoglue F., $J$. Alloy. Compd., 515 (2012), 96.

[7] DAKHel A.A., Thin Solid Films, 518 (2010), 1712.

[8] Serbetci Z., Gupta R.K., Yakuphanoglue F., J. Sol-Gel Sci. Techn. 61 (2012), 477.

[9] Biasi De R.S., Grillo M.L.N., J. Alloy. Compd., 485 (2009), 26.
[10] Ahmad T., Khatoon S., Coolahan K., Lofland SE., J. Alloy. Compd., 558 (2013), 117.

[11] Sivaraman T., Balu A.R., Nagarethinam V.S., Mat. Sci. Semicon. Proc., 27 (2014), 915.

[12] Shanmugavel G., Balu A.R., Nagarethinam V.S., Int. J. Chem. Mat. Res., 2 (2014), 88.

[13] Abdolohzadeh Ziabari A., Ghodsi F.E., KIRIAKIDIS G., Surf. Coat. Tech., 213 (2012), 15.

[14] Manjula N., Balu A.R., Int. J. Chem. Phys. Sci., 3 (2014), 54

[15] Zheng B.J., LiAn J.S., ZHAO L., JiAng Q., Vacuum, 85 (2011), 861.

[16] Sayed El A.M., Ali Ibrahim, Mat. Sci. Semicon. Proc., 26 (2014), 320.

[17] Balu A.R., Nagarethinam V.S., Syed Basheer Ahamed M.G., Thayumanavan A., Murali K.R., SANJEEVIRAJA C., SWAMinathan V., JAYACHANDRAN M., Mater. Sci. Eng. B-Adv., 171 (2010), 93.

[18] Mallika A.N., Ramachandra Reddy A., Sowri Babu K., Sujatha CH., Venugopal Reddy K., Opt. Mater, 36 (2014), 879.

[19] DE Biassi R.S., Grillo M.L.N., Ceram. Int., 39 (2013), 2171.

[20] He R., Hocking R.K., Tsuzuki T., Mater. Chem. Phys., 132 (2012), 1035.

[21] Sankarasubramanian K., Soundarrajan P., Logu T., Kiruthika S., Sethuraman K., Ramesh Babu R., Ramamurthi K., Mat. Sci. Semicon. Proc., 26 (2014), 346.

[22] Kavasoglu N., Kavasoglur S.A., OKtik S., J. Phys. Chem. Solids, 70 (2009), 521.

[23] Zeng H., Duan G., Li Y., Yang S., Xu X., CaI W., Adv. Funct. Mater., 20 (2010), 561.

[24] FAng C.S., GU Q.T., Wei J.Q., PAN Q.W., Shi W., WANG J.Y., J. Cryst. Growth, 209 (2000), 542.

Received 2014-12-24 Accepted 2015-09-29 